\title{
`R-RAFT or Z-RAFT? Well-defined Star Block Copolymer Nano-objects prepared by RAFT-Mediated Polymerization-Induced Self-Assembly
}

\author{
Ruiming Zeng ${ }^{\mathrm{a}}$, Ying Chen ${ }^{\mathrm{b}}$, Li Zhang ${ }^{\mathrm{a}, \mathrm{b}}$, Jianbo Tan $^{* a, b}$ \\ a. Department of Polymeric Materials and Engineering, School of Materials and Energy, \\ Guangdong University of Technology, Guangzhou 510006, China. \\ b. Guangdong Provincial Key Laboratory of Functional Soft Condensed Matter, Guangzhou 510006, \\ China.
}

*Corresponding authors: tanjianbo@gdut.edu.cn 


\section{EXPERIMENTAL SECTION}

\section{Material}

$N, \quad N$-Dimethylacrylamide (DMA, Aladdin), ethylene glycol (EG, Aladdin), trimethylolpropane (TMP, Aladdin), dicyclohexylcarbodiimide $\quad$ (DCC, Aladdin),4-dimethylaminopyridine (DMAP, Aladdin), and hydroquinone (Aladdin) were used as received. 2, 2-Azobisisobutyronitrile (AIBN, Aladdin) was recrystallized from ethanol prior to storage under refrigeration at $4{ }^{\circ} \mathrm{C} .2$, 4, 6-trimethylbenzoyldi-phenylphosphinate (TPO, Ciba) was used without further purification. $N$-isopropylacrylamide (NIPAM, Aladdin) was recrystallized from hexane prior to storage under refrigeration at $4{ }^{\circ} \mathrm{C}$. Styrene (St, Aladdin) and isobornyl acrylate (IBOA, Sigma-Aldrich) were purified by passing through a basic alumina oxide (Aladdin) column prior to storage at $4{ }^{\circ} \mathrm{C}$. 3-(Benzylthiocarbonothioylthio)propanoic acid (BTPA) was synthesized according to a published $\quad$ procedure. ${ }^{1} \quad$ Pentaerythritoltetrakis-(3-(S-benz-yltrithiocarbonyl)propionate) $\left((\mathrm{TTC}-\mathrm{Z})_{4}\right)$ was synthesized according to a published procedure. $^{2} 1,2,4$, 5-tetrakis-(butyltrithiomethyl)benzene ((TTC-R)4)was synthesized according to a published procedure. $^{3}$

\section{Characterization}

Transmission Electron Microscopy (TEM). The polymerization reaction mixtures were diluted 100-fold with methanol/water mixtures. A drop of the solution was placed on the copper grid for $1 \mathrm{~min}$ and then blotted with filter paper to remove excess solution. TEM 
observations were carried out on a HT7700 instrument operated at $100 \mathrm{kV}$. TEM images were analyzed by using the software program named Image pro Plus 6.0.

Scanning electron microcopy (SEM). SEM images were collected using a Hitachi SU8010 (Tokyo, Japan) electron microscope on samples sputter-coated with gold prior imaging. The sample for SEM imaging was prepared by drop casting the diluted dispersion on a clean mica films and drying at room temperature prior to sputter-coating.

Gel Permeation Chromatography (GPC). The molecular weight and polydispersity of polymers were measured by GPC at $35{ }^{\circ} \mathrm{C}$ using a Waters 1515 GPC instrument with tetrahydrofuran (THF) as the mobile phase and Waters Styragel HR1, HR4 columns. The flow rate of THF was $1.0 \mathrm{~mL} / \mathrm{min}$. Linear polystyrene polymers with narrow molecular weight distributions were used as the standards to calibrate the apparatus.

${ }^{1} \mathrm{H}$ NMR Spectroscopy. ${ }^{1} \mathrm{H}$ NMR spectra were recorded in $\mathrm{CDCl}_{3}$ using a Bruker Avance III $400 \mathrm{MHz}$ NMR spectrometer at a temperature of $25^{\circ} \mathrm{C}$. Note: The samples prepared by PISA were first diluted with methanol, and then dissolved in $\mathrm{CDCl}_{3}$.

Ultraviolet visible photometer. UV-Visible spectra were recorded with a $1.0 \mathrm{~cm}$ quartz cuvette using a UV2450 spectrometer.

\section{Synthesis of Multifunctional Trithiocarbonates}

Synthesis of $(\text { TTC-Z) })_{2}$ A solution of BTPA $(8.41 \mathrm{~g}, 30.92 \mathrm{mmol})$ in $30 \mathrm{~mL}$ of anhydrous tetrahydrofuran was introduced in a dry flask containing EG $(0.80 \mathrm{~g}, 12.88 \mathrm{mmol})$. Then a solution of DCC $(6.37 \mathrm{~g}, 30.92 \mathrm{mmol})$ and DMAP $(0.377 \mathrm{~g}, 3.092 \mathrm{mmol})$ in $5 \mathrm{~mL}$ of anhydrous tetrahydrofuran was added dropwise to the reaction mixture at $0{ }^{\circ} \mathrm{C}$. The 
esterification reaction proceeded under stirring at room temperature for $24 \mathrm{~h}$. After the removal of solvent in vacuo, the crude product was purified using column chromatography on silica eluting with petroleum ether/dichloromethane (1: 1) and finally dried at $45{ }^{\circ} \mathrm{C}$ under vacuum to obtain a viscous orange oil.

Synthesis of $(\text { TTC-Z) })_{3}$. A solution of BTPA $(5.84 \mathrm{~g}, 21.47 \mathrm{mmol})$ in $25 \mathrm{~mL}$ of anhydrous tetrahydrofuran (THF) was introduced in a dry flask containing TMP $(0.80 \mathrm{~g}, 5.96 \mathrm{mmol})$. Then a solution of DCC $(4.12 \mathrm{~g}, 21.47 \mathrm{mmol})$ and DMAP $(0.244 \mathrm{~g}, 2.15 \mathrm{mmol})$ in $5 \mathrm{~mL}$ of anhydrous tetrahydrofuran was added dropwise to the reaction mixture at $0{ }^{\circ} \mathrm{C}$. The esterification reaction proceeded under stirring at room temperature for $24 \mathrm{~h}$. After the removal of solvent in vacuo, the crude product was purified using column chromatography on silica eluting with dichloromethane and finally dried at $45{ }^{\circ} \mathrm{C}$ under vacuum to obtain a viscous orange oil.

\section{Synthesis of 1-, 2-, 3-, and 4-arm star macro-RAFT agents}

In a typical experiment for the synthesis of 4-arm star macro-RAFT agent, DMA (15.0 g, $151.3 \mathrm{mmol}),(\text { TTC-Z) })_{4}(2.09 \mathrm{~g}, 1.89 \mathrm{mmol})$, AIBN (25 mg, $\left.0.15 \mathrm{mmol}\right), \quad 1,3$, 5-trioxacyclohexane (1.37 g, $15.13 \mathrm{mmol})$, and 1, 4-dioxane ( $35.0 \mathrm{~g})$ were weighed into a 100 $\mathrm{mL}$ round bottom flash and purged with nitrogen for $30 \mathrm{~min}$. The flask was then immersed into a preheated oil bath at $70{ }^{\circ} \mathrm{C}$ for $4 \mathrm{~h}$ (Monomer conversion $=97 \%$ as judged by ${ }^{1} \mathrm{H}$ NMR). The polymerization was then quenched by immersion in ice water and exposure to air. The product was precipitated by adding excess of hexane and washed several times with 
additional hexane. The precipitated product was then dried at $45^{\circ} \mathrm{C}$ under vacuum overnight. Other macro-RAFT agents were synthesized following the same protocol.

\section{Star block copolymer nano-objects prepared by RAFT-mediated dispersion polymerization}

In a typical experiment for the synthesis of $\left(\mathrm{PDMA}_{20}-\mathrm{PSt}_{150}-\mathrm{TTC}-\mathrm{Z}\right)_{4}(20 \% \mathrm{w} / \mathrm{w} \mathrm{St}), \mathrm{St}$ (1.50 g, $14.4 \mathrm{mmol}),\left(\mathrm{PDMA}_{20}-\mathrm{TTC}-\mathrm{Z}\right)_{4}(0.217 \mathrm{~g}, 0.024 \mathrm{mmol})$, and AIBN (5.2 mg, 0.032 mmol) were weighed into a $25 \mathrm{~mL}$ round bottom flask. Then a methanol/water mixture (4.8 $\mathrm{g} / 1.2 \mathrm{~g}$ ) was added into the flask to dissolve all reagents. The reaction was purged with nitrogen for $20 \mathrm{~min}$, and then immersed into a pre-heated oil bath at $70{ }^{\circ} \mathrm{C}$ for $24 \mathrm{~h}$. The reaction was quenched by immersing into an ice-water bath.

\section{Kinetic Study of RAFT-mediated dispersion polymerization}

In a typical experiment, St $(2.50 \mathrm{~g}, 24.0 \mathrm{mmol}),\left(\mathrm{PDMA}_{20}-\mathrm{TTC}-\mathrm{Z}\right) 4(0.269 \mathrm{~g}, 0.030$ mmol), AIBN (6.6 mg, $0.040 \mathrm{mmol})$ and 1,3,5-trioxacyclohexane $(0.21 \mathrm{~g}, 2.4 \mathrm{mmol})$ were weighed into a $25 \mathrm{~mL}$ round bottom flask. Then a methanol/water mixture $(8.0 \mathrm{~g} / 2.0 \mathrm{~g})$ was added into the flask to dissolve all reagents. The reaction mixture was purged with nitrogen for $20 \mathrm{~min}$, and then immersed into a pre-heated oil bath at $70{ }^{\circ} \mathrm{C}$ for $24 \mathrm{~h}$. Samples were withdrawn at predetermined time intervals by syringes under nitrogen, and the reaction was quenched by immersing into an ice-water batch and adding a small amount of hydroquinone.

The samples were then analyzed by ${ }^{1} \mathrm{H}$ NMR spectroscopy and gel permeation chromatography (GPC). 


\section{Synthesis of 4-arm triblock copolymer nano-objects by seeded RAFT dispersion}

polymerization

Synthesis of (PDMA $\left.20-P S t_{150}-T T C-Z\right)_{4}$ vesicles. St (1.50 g, $\left.14.4 \mathrm{mmol}\right)$, AIBN (5.2 mg, $0.032 \mathrm{mmol})$, and $\left(\mathrm{PDMA}_{20}-\mathrm{TTC}-\mathrm{Z}\right)_{4}(0.217 \mathrm{~g}, 0.024 \mathrm{mmol})$ were weighed into a $25 \mathrm{~mL}$ round bottom flask. Then a methanol/water mixture $(4.8 \mathrm{~g} / 1.2 \mathrm{~g})$ was added into the flask to dissolve all reagents. The reaction mixture was purged with nitrogen for $20 \mathrm{~min}$, and then immersed into a pre-heated oil bath at $70{ }^{\circ} \mathrm{C}$ for $24 \mathrm{~h}$.

Synthesis of (PDMA $\left.20-P S t_{148}-P N I P A M_{200}-T T C-Z\right)_{4}$ assemblies. NIPAM (2.1735 g, 19.2 $\mathrm{mmol})$ and $\operatorname{AIBN}(5.2 \mathrm{mg}, 0.032 \mathrm{mmol})$ were dissolved in a methanol/water mixture (12.83 $\mathrm{g} / 3.21 \mathrm{~g}$ ). The solution was purged with nitrogen for $20 \mathrm{~min}$, and then injected into the dispersion of $\left(\mathrm{PDMA}_{20}-\mathrm{PSt}_{148}-\mathrm{TTC}-\mathrm{Z}\right)_{4}$ vesicles at $70{ }^{\circ} \mathrm{C}$. The polymerization was continued for another $24 \mathrm{~h}$. The reaction was quenched by exposure to air and immersing in an ice-water bath.

Synthesis of (PDMA $\left.20-P S t_{148}-P I B O A_{100}-T T C-Z\right)_{4}$ assemblies. IBOA (2.00 g, $\left.9.6 \mathrm{mmol}\right)$ and AIBN (5.2 mg, $0.032 \mathrm{mmol})$ were dissolved in a methanol/water mixture $(12.03 \mathrm{~g} / 3.01 \mathrm{~g})$. The solution was purged with nitrogen for $20 \mathrm{~min}$, and then injected into the dispersion of $\left(\mathrm{PDMA}_{20}-\mathrm{PSt}_{148}-\mathrm{TTC}-\mathrm{Z}\right)_{4}$ vesicles at $70{ }^{\circ} \mathrm{C}$ for $24 \mathrm{~h}$. The reaction was quenched by exposure to air and immersing in an ice-water bath.

\section{Removal of trithicarbonate group from the 4-arm star block copolymers}

$\left(\mathrm{PDMA}_{20}-\mathrm{PSt}_{200}-\mathrm{TTC}-\mathrm{Z}\right)_{4}(0.87 \mathrm{~g})$ was dissolved in $4.33 \mathrm{~g}$ THF in a $10 \mathrm{~mL}$ round bottom flask. Then 50-fold photoinitiator (2,4,6-trimethylbenzoyldiphenyl phosphine oxide) was 
added to the reaction mixture. The reaction was then purged with nitrogen for $20 \mathrm{~min}$, and then irradiated by a visible light LED lamp $\left(405 \mathrm{~nm}, 3 \mathrm{~mW} / \mathrm{cm}^{2}\right)$ for $5 \mathrm{~h}$. The samples were then analyzed by GPC directly.

\section{Additional results}

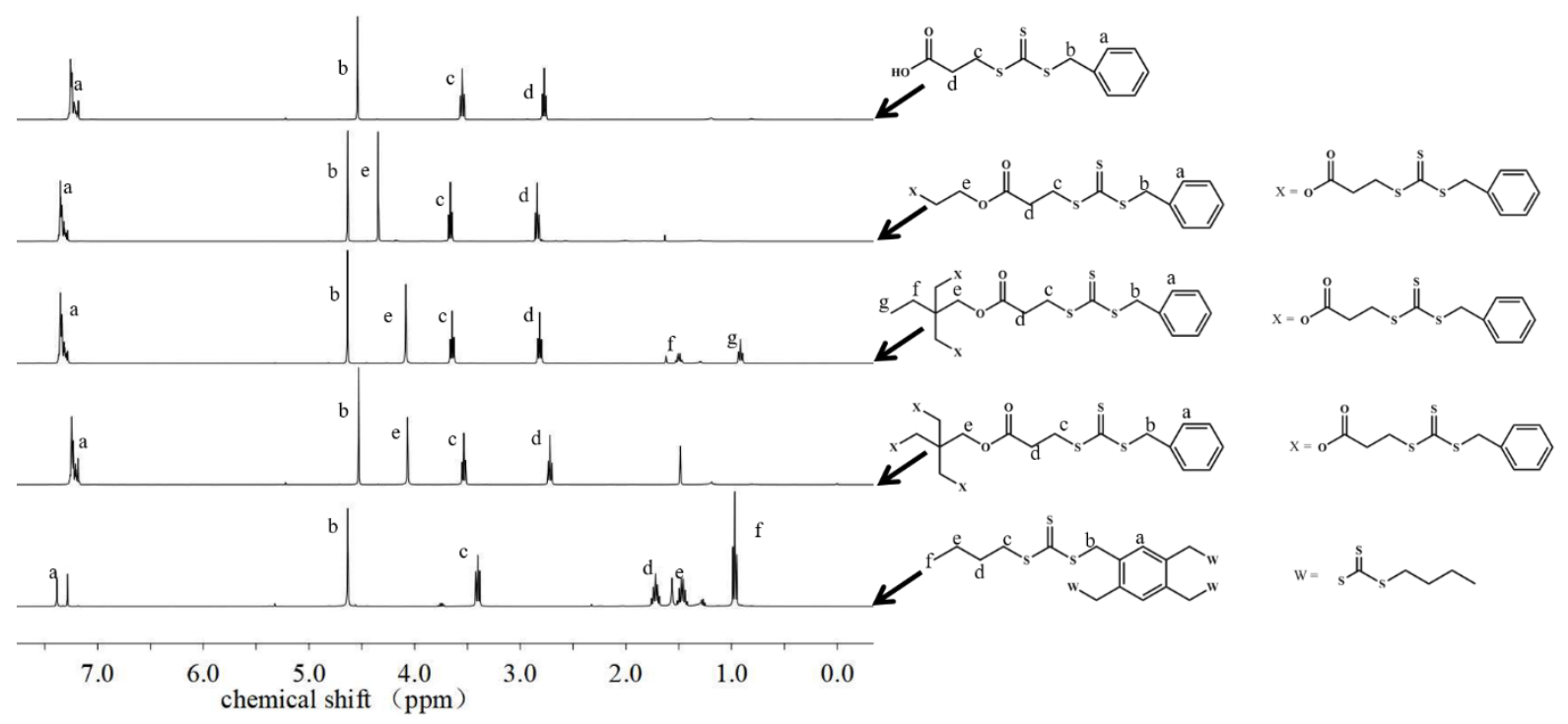

Figure S1. ${ }^{1} \mathrm{H}$ NMR spectra of small molecular RAFT agents used in the present study.
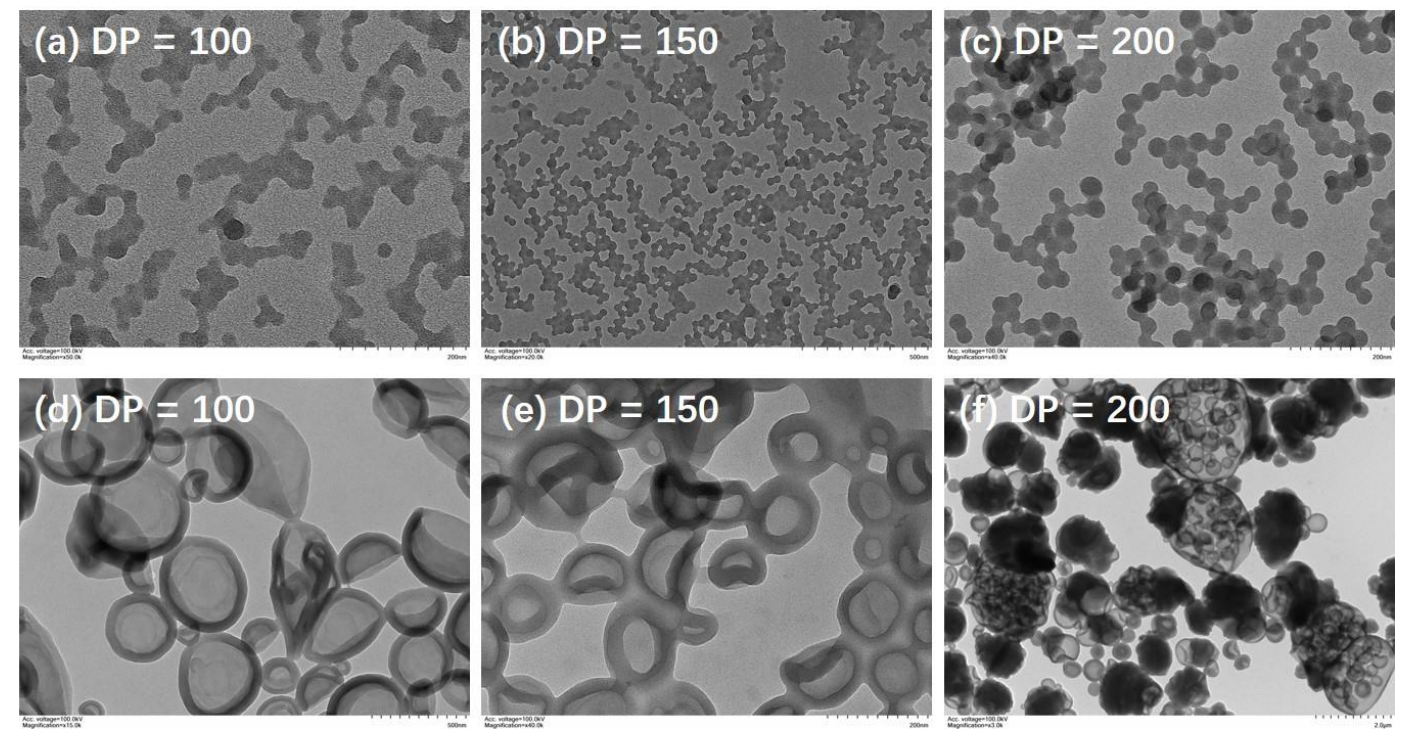

Figure S2. (a-c) TEM images of (PDMA $\left.27-P S t_{n}-T T C-Z\right)_{4}$ star block copolymer nano-objects prepared by RAFT-mediated PISA of St using (PDMA $27-T T C-Z)_{4}$. (d-f) TEM images of (PDMA ${ }_{13}-$ PSt $_{n}-$ TTC-Z $_{4}$ star block copolymer nano-objects prepared by RAFT-mediated PISA of St using (PDMA $13-T T C-Z)_{4}$. 


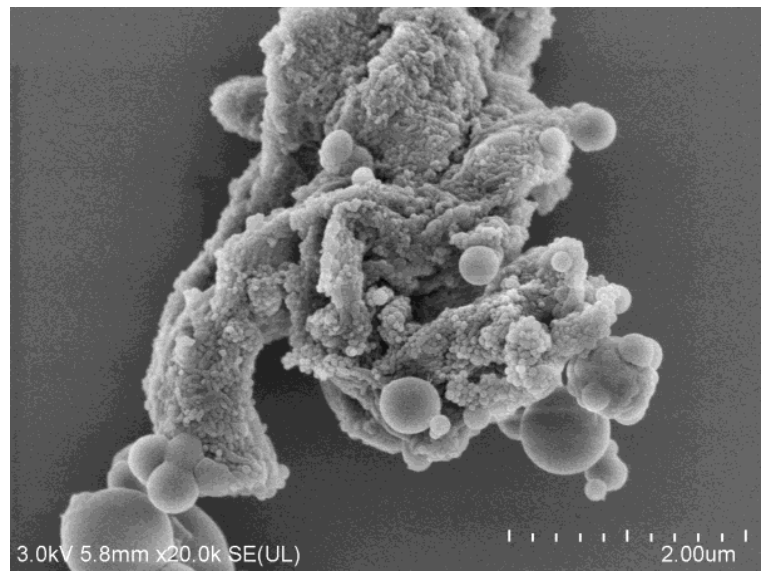

Figure S3. SEM image of (TTC-PSt200-PDMA27-R) ${ }_{4}$ prepared by RAFT-mediated PISA of St using $(\text { TTC-PDMA } 27-R)_{4}$.
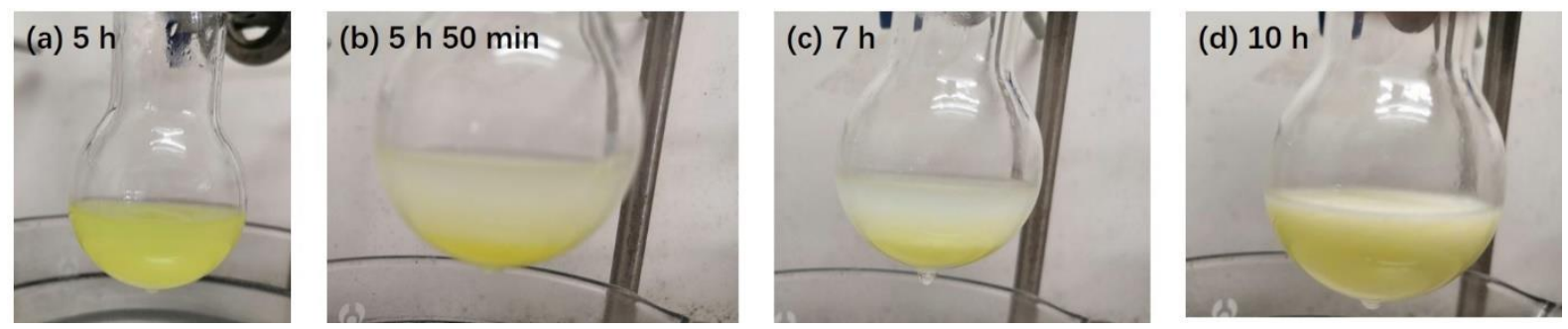

Figure S4. Optical images of reaction mixture of RAFT-mediated PISA of St $(20 \% \mathrm{w} / \mathrm{w})$ using $(\text { TTC-PDMA } 20-R)_{4}$ in a methanol/water $(80 / 20, w / w)$ mixture.

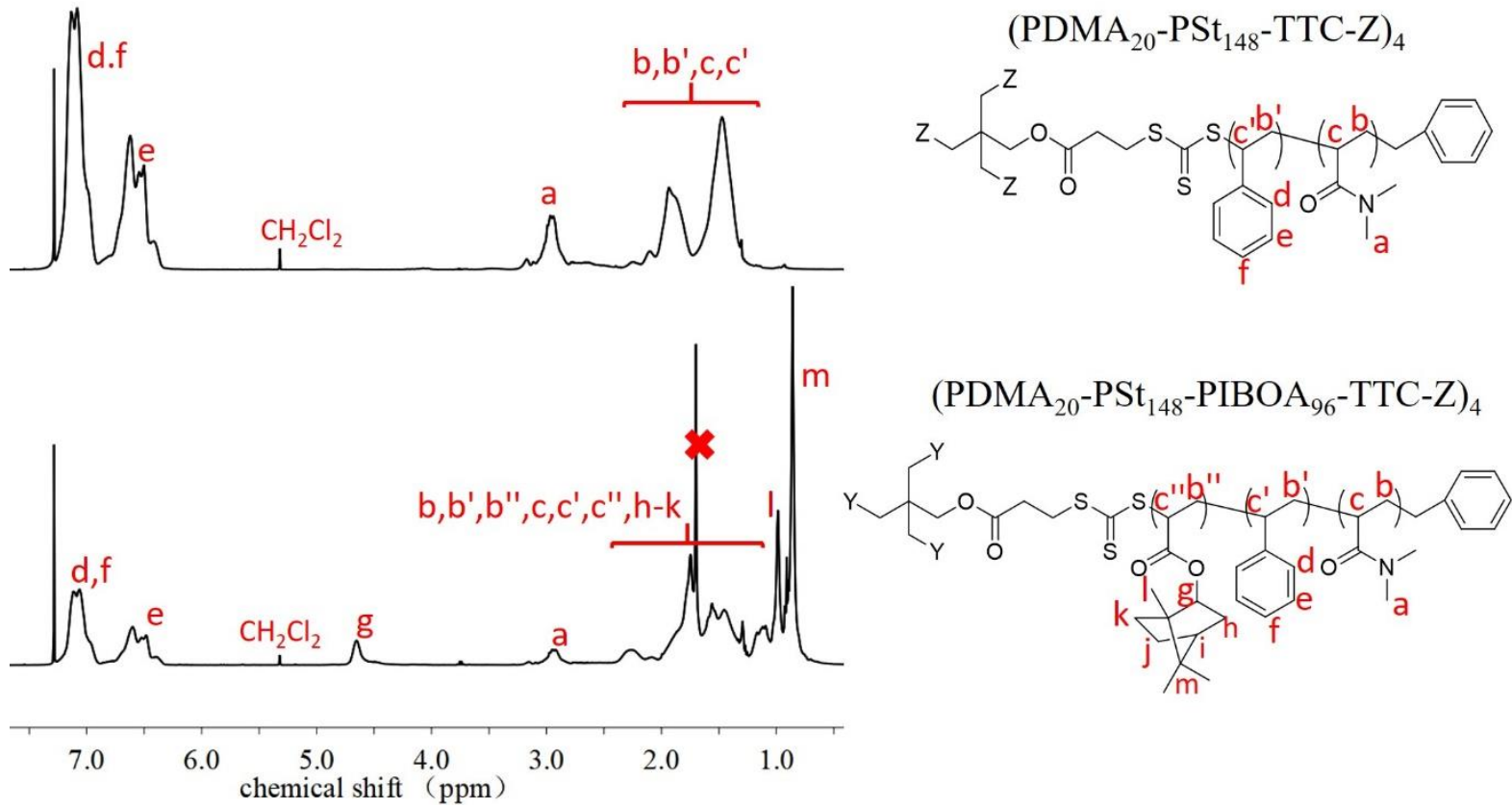

Figure S5. ${ }^{1} \mathrm{H}$ NMR spectra of (PDMA $\left.20-P S t_{148}-T T C-Z\right) 4$ and $\left(P_{2 M A}{ }_{20}-P S t_{148}-P I B O A 96-T T C-Z\right) 4$. 

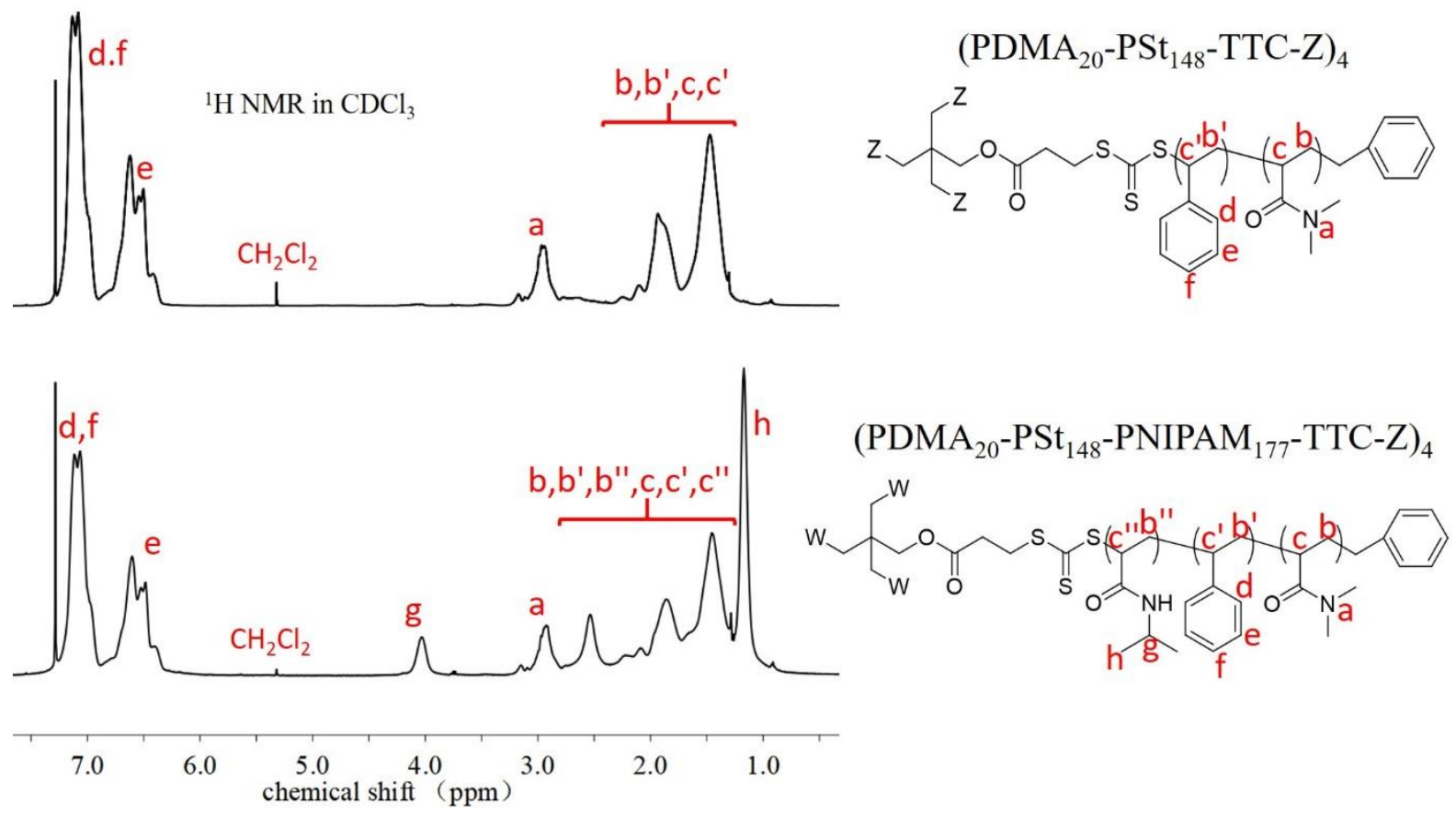

Figure S6. ${ }^{1} \mathrm{H}$ NMR spectra of (PDMA $\left.20-\mathrm{PSt}_{148}-\mathrm{TTC}-\mathrm{Z}\right)_{4}$ and $\left(\mathrm{PDMA}_{20}-\mathrm{PSt}_{148}-\mathrm{PNIPAM}_{177-T T C-Z}\right)_{4}$

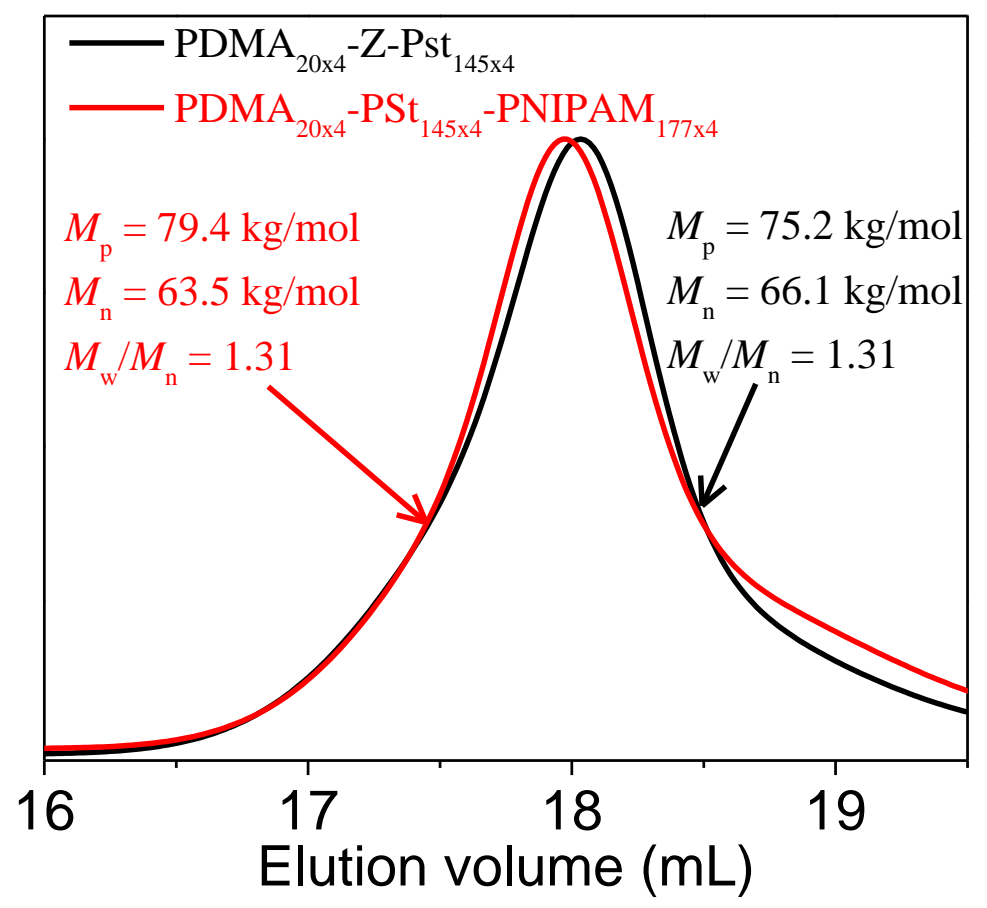

Figure S7. GPC traces of $\left(\mathrm{PDMA}_{20}-\mathrm{PSt}_{148}-\mathrm{TTC}-\mathrm{Z}\right)_{4}$ and $\left(\mathrm{PDMA}_{20}-\mathrm{PSt}_{148}-\mathrm{PNIPAM}_{177}-\mathrm{TTC}-\mathrm{Z}\right)_{4}$. 
Table S1. GPC data of macro-RAFT agents used in the present study.

\begin{tabular}{ccc}
\hline Macro-RAFT agent & $M_{\mathrm{n}}(\mathrm{kg} / \mathrm{mol})^{\mathrm{a}}$ & $M_{\mathrm{w}} / M_{\mathrm{n}}{ }^{\mathrm{a}}$ \\
\hline (TTC-PDMA $\left._{20}-\mathrm{R}\right)_{4}$ & 7.4 & 1.03 \\
$\left(\mathrm{PDMA}_{20}-\mathrm{TTC}-\mathrm{Z}\right)_{4}$ & 7.2 & 1.05 \\
PDMA $\left._{13}-\mathrm{TTC}-\mathrm{Z}\right)_{4}$ & 5.2 & 1.07 \\
$\left(\mathrm{PDMA}_{27}-\mathrm{TTC}-\mathrm{Z}\right)_{4}$ & 8.2 & 1.06 \\
PDMA $_{21}$-TTC-Z & 2.5 & 1.09 \\
$\left(\mathrm{PDMA}_{22}-\mathrm{TTC}-\mathrm{Z}\right)_{2}$ & 4.7 & 1.07 \\
$\left(\text { PDMA }_{21}-\mathrm{TTC}-\mathrm{Z}\right)_{3}$ & 6.5 & 1.04 \\
\hline
\end{tabular}

${ }^{a}$ Based on the GPC measurement against polystyrene standards.

\section{REFERENCES}

(1) Dag, A.; Zhao, J.; Stenzel, M. H. Origami with ABC Triblock Terpolymers Based on Glycopolymers: Creation of Virus-Like Morphologies. ACS Macro Lett. 2015, 4 (5), 579-583. https://doi.org/10.1021/acsmacrolett.5b00163.

(2) Skey, J.; Willcock, H.; Lammens, M.; Du Prez, F.; O'Reilly, R. K. Synthesis and Self-Assembly of Amphiphilic Chiral Poly(Amino Acid) Star Polymers. Macromolecules 2010, 43 (14), 5949-5955. https://doi.org/10.1021/ma101019g.

(3) Qu, Y.; Chang, X.; Chen, S.; Zhang, W. In Situ Synthesis of Thermoresponsive 4-Arm Star Block Copolymer Nano-Assemblies by Dispersion RAFT Polymerization. Polym. Chem. 2017, 8 (22), 34853496. https://doi.org/10.1039/C7PY00508C. 